\title{
Geomagnetic sudden commencement at the dawn-time dip equator
}

\author{
De-Sheng $\operatorname{Han}^{1}$ and Qi $\mathrm{Li}^{2}$ \\ ${ }^{1}$ SOA Key Laboratory for Polar Science, Polar Research Institute of China, Shanghai, China \\ ${ }^{2}$ Institute of Geophysics, China Earthquake Administration, Beijing, China
}

(Received September 22, 2007; Revised December 26, 2007; Accepted January 4, 2008; Online published July 4, 2008)

\begin{abstract}
Waveform of geomagnetic sudden commencement (SC) on the ground depends on both latitude and local time (LT). Using high-resolution ( $1 \mathrm{~s})$ geomagnetic field measurements obtained at Jicamarca $\left(\mathrm{JIC}\right.$, MAGLAT $=0.0^{\circ}$ ) from 1998 to 2005, we examined the waveforms of 188 SC events and found that some of the SCs observed at nighttime (approx. 22-05 LT) and dawn time (approx. 05-07 LT) had a common observational feature, i.e., a positive impulse always appeared at the beginning of the main impulse of the SC, which led to these events show preliminary positive impulse (PPI) or 'Stepwise' structure in the waveforms. In particular, the occurrence rate of the PPI/Stepwise events at the dawn time was clearly higher than that at the nighttime. This is the first complete report of this observational feature for the SCs observed at the dip equator. Based on a comparison of our observations with the previously proposed model calculation of Kikuchi et al. (2001), we suggest that the PPI/Stepwise events observed at the dawn-time dip equator reflect the effects of the ionospheric currents (ICs) and field-aligned currents (FACs). We therefore argue that this observational result provides evidence for the validity of the model calculation.
\end{abstract}

Key words: SC at dawn-time dip equator, DP-field current model, PPI.

\section{Introduction}

A sudden increase in the solar wind dynamic pressure can generally cause a global response in the form of a geomagnetic sudden commencement (SC) (Russell et al., 1992, 1994a, b; Russell and Ginskey, 1995). The ground response of SCs (including sudden impulses, SIs) normally manifests as a step-like increase in the $H$ component and is sometimes accompanied with a preliminary reverse impulse (PRI) or preliminary positive impulse (PPI). The global distribution of SC waveforms depends on both latitude and local time (LT). The distribution and generation of PRIs have been extensively studied since 1960s (e.g., Tamao, 1964; Araki, 1994 and references therein). The LT profile of the waveform of SCs from low to subauroral latitudes has been studied by many researchers (e.g., Russell et al., 1992, 1994a, b; Russell and Ginskey, 1995). It has been found that at the subauroral latitudes, the waveform of SCs generally shows a PRI followed by a main impulse (MI) in the afternoon, with reversed magnetic variation in the morning (Araki, 1977). The PRIs also appear at the dayside dip equator with enhanced amplitude, but the latter are rarely observed at low latitudes (Araki, 1977, 1994). Kikuchi and Araki (1985) were the first to notice that a PPI occasionally precedes a SC at the mid and low latitudes on the dayside and suggested that the PPI is transmitted from above the ionosphere by a compressional hydromagnetic wave rather than being produced by ionospheric currents generated in the polar region. Tsunomura (1998) examined the PPIs at mid lat-

Copyright (c) The Society of Geomagnetism and Earth, Planetary and Space Sciences (SGEPSS); The Seismological Society of Japan; The Volcanological Society of Japan; The Geodetic Society of Japan; The Japanese Society for Planetary Sciences; TERRAPUB itudes in the morning and suggested that they are consistent with a model calculation of Tsunomura and Araki (1984), in which the effects of the ionospheric currents (ICs) are the main factors to be considered. Kikuchi et al. (2001) subsequently examined the PPIs that appeared at mid latitudes and the dip equator in the afternoon by considering the effects of field-aligned currents (FACs) and the existence of differences in the ionospheric conductivities between the winter and summer hemispheres. These researchers concluded that the PPIs at mid latitudes in the afternoon were dominated by the magnetic effects of the FACs that carry the electric fields responsible for the PRIs (Kikuchi et al., 2001).

The ground level response to magnetospheric disturbances always presents special properties at the dip equator. For example, in addition to SCs (Araki, 1977), many phenomena, such as Pi2 (Shinohara et al., 1998) and Pi3/Pc5 pulsations (e.g., Han et al., 2007a; Motoba et al., 2002) have amplitude enhancements at the dayside dip equator. The SCs at the dip equator are often preceded by PRIs on the dayside, while they normally show simple steplike increases on the nightside (Matsushita, 1962). Using rapid-run magnetograms from Guam (GUM, MAGLAT = $4.2^{\circ} \mathrm{N}$ ), Araki et al. (1985) observed that there were two kinds of SCs during the nighttime: the ordinary SC with a simple step-like increase in the $H$ component, and one with a much steeper stepwise increase of the $H$ component superposed on the smooth increase of SC; the latter is called the Stepwise SC. Araki et al. (1985) found that the maximum occurrence of the Stepwise SC was at 0300 LT and interpreted this observation as indicating that the Stepwise SCs were produced by an extension of a polar IC to the nightside equator. The 'Stepwise SC' near the dip equator 
studied by Araki et al. (1985) could be intimately related to the PPI defined by Kikuchi and Araki (1985), but further studies are necessary to confirm the waveform characteristics of SC at the dip equator in detail.

We have examined SCs observed at Jicamarca (JIC, MAGLAT $=0.0^{\circ} \mathrm{N}$ ) at the dip equator and obtained some new observational results. We believe that detailed examination of these events is necessary to complement our understanding of the ground response to the sudden changes of solar wind parameters.

\section{Observations}

The high time-resolution ( $1 \mathrm{~s})$ geomagnetic field data obtained at Jicamarca $\left(\mathrm{JIC}\right.$, MAGLAT $=0.0^{\circ}$ ) between 1998 and 2005 are the main data sets used in this study. During this time period, $188 \mathrm{SC}$ events were detected at JIC. Figure 1 gives the LT distribution of the total events, normal SCs (defined as a simple step-like increase in the $H$ component), PRI events, and PPI/Stepwise events, respectively. The PPI/Stepwise events have a common feature: a positive impulse appears at the very beginning of the smooth rise of the main impulse. The events in which the initial positive impulse had a relatively larger amplitude were called as PPI events by Kikuchi and Araki (1985), and those with relatively smaller amplitude of the initial positive impulse were called as Stepwise events by Araki et al. (1985). Therefore, in order to maintain consistency with previous studies, we have denoted the events having positive impulses at the very beginning of the SC as PPI/Stepwise events.

Figure 1 shows that the PRIs predominantly occur on the dayside, which is consistent with what was summarized in Araki (1994) for the dip-equator observations. Figure 1 also indicates that the PPI/Stepwise events are mainly observed at nighttime (approx. 22-05 LT) and near dawn (approx. 05-07 LT). Table 1 gives the occurrence rate of the PPI/Stepwise events during the time period of approximately 22-07 LT at JIC. Based on the data provided in this table, it is clear that the occurrence rate of the PPI/Stepwise event at the dawn time (05-07 LT, 69\%) is much higher than that during the nighttime (22-05 LT, 13\%).

The eight panels in Fig. 2 plot the PPI/Stepwise events observed between approximately 22 and 05 LT at JIC. The date (in the format of YYMMDD) and approximate onset time of the SC in LT at JIC are given at the top of each panel. Observations at Kakioka (KAK, MAGLAT $=27.3^{\circ} \mathrm{N}$ ) are also given to enable a comparison of the waveforms for each event. The nine panels in Fig. 3 (denoted by numbers in parenthesis) show the waveforms for the PPI/Stepwise events observed at JIC at the dawn time (05-07 LT). Note that events '2', '3', '5', '6', and ' 8 ' in Fig. 3 can be called PPI events according to the definition of Kikuchi and Araki (1985) and that all of the other events shown in Figs. 2 and 3 can be called Stepwise events according to Araki et al. (1985).

In Fig. 3, the SCs observed at two low-latitude stations that are longitudinally separated by several hours are also given in each panel for comparison with the waveform at JIC. One of the low-latitude stations is KAK and another is Alibag $\left(\right.$ ABG, MAGLAT $\left.=10.0^{\circ} \mathrm{N}\right)$ or Tamanrasset $($ TAM, MAGLAT $\left.=24.7^{\circ} \mathrm{N}\right)$. The SCs observed at the low lati-

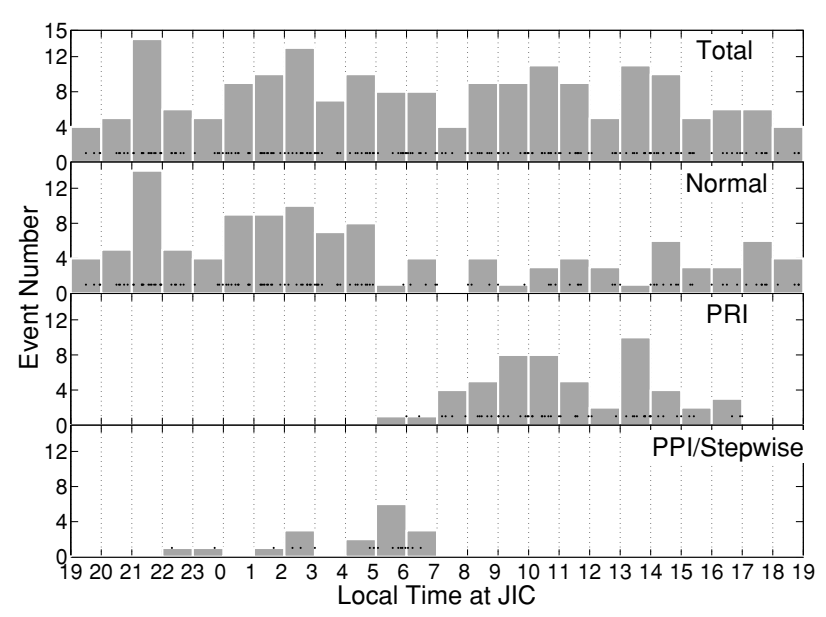

Fig. 1. The total, normal, PRI, PPI/Stepwise SCs detected at JIC from 1998 to 2005 distributed with local time at JIC. The black dot indicates the occurrence time for the individual event.

Table 1. Occurrence rate of the PPI/Stepwise events during the time period of 22-07 LT at JIC.

\begin{tabular}{ccc}
\hline & $22-05$ LT & $05-07$ LT \\
\hline Total: & 60 & 13 \\
PPI \& Stepwise event & $8(13 \%)$ & $9(69 \%)$ \\
\hline
\end{tabular}

tudes experience less of an effect from both the auroral and equatorial electrojets (Russell et al., 1992), so comparison of the waveforms between JIC and the low-latitude stations can display the 'unique characteristic' of SC waveforms observed at the dip equator. The red, green, and blue curves in each panel of Fig. 3 show the SC observed at JIC, KAK, and ABG, respectively. Observations at TAM instead of ABG were used in event ' 1 ' due to the lack of observation at ABG for this event. The date (in the format of YYMMDD) and approximate onset time of the SC in LT at JIC are given at the top of each panel. Coordinates of the ground stations used in this study are given in Table 2 .

In Fig. 3, the black curve in each panel shows the waveform of an artificial field of $\delta H$, which is obtained by subtracting the SC field observed at KAK from that at JIC $\left(\delta H=H_{\mathrm{JIC}}-H_{\mathrm{KAK}}\right)$. We note that the $\delta H$ shows similar waveform for all of the events-i.e., a positive increase followed by a decrease.

\section{Discussion}

\subsection{Comparison with previous observations}

As mentioned in Introduction, since the first observation of the PPI by Kikuchi and Araki (1985), no detailed analysis of the PPI at the dip equator has been carried out. Using rapid-run magnetograms obtained from GUM, a station near the dip equator, Araki et al. (1985) observed that part of the SCs observed in the nighttime always have a small positive impulse at the very beginning of the smooth rise of the main impulse. Araki et al. (1985) called these events 'Stepwise' events and found that their maximum occurrence rate occurred at 03 LT. The authors suggested that the Stepwise SCs were produced by an extension of a polar IC to the nightside equator. In this study, Fig. 1 shows that even though there is a peak in the occurrence of the PPI/Stepwise 

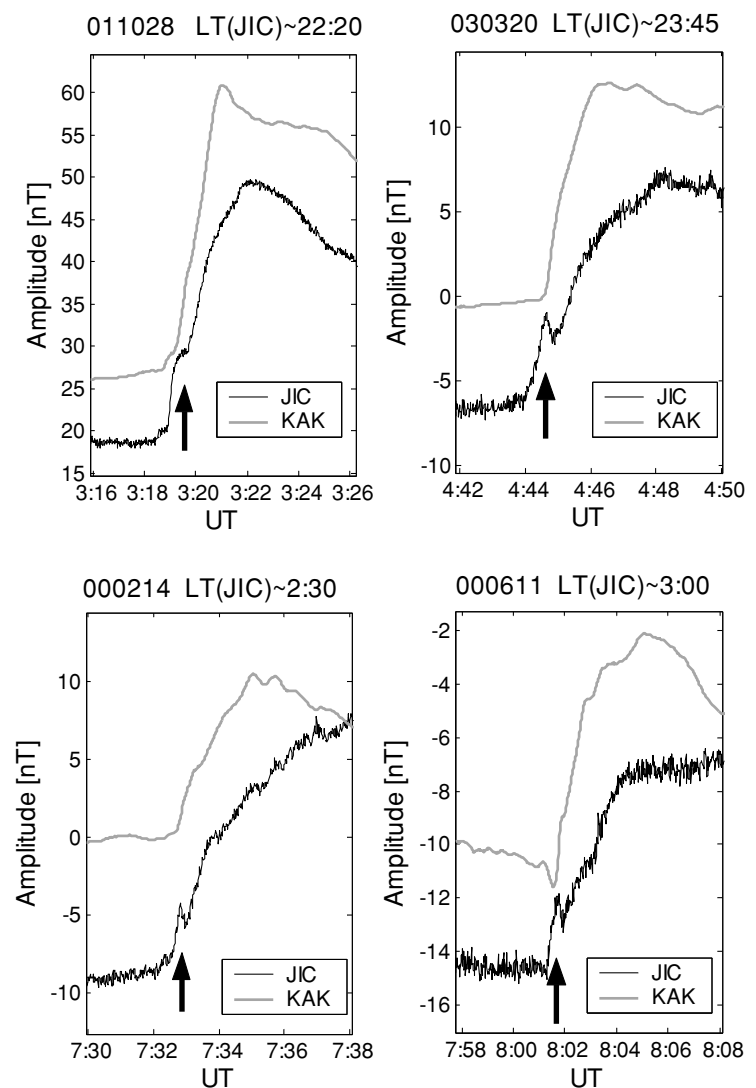
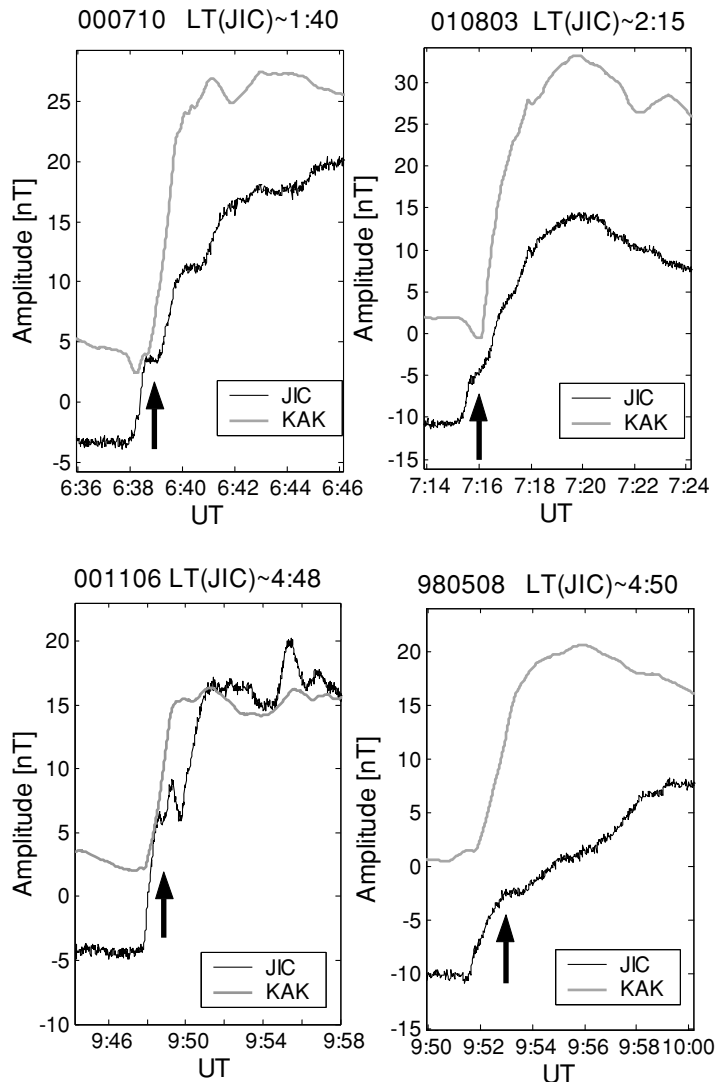

Fig. 2. The eight PPI/Stepwise SCs observed at JIC and KAK during the nighttime (22-05 LT) at JIC.

events near approximately 03 LT, as found by Araki et al. (1985), the maximum occurrence peak is during the dawn time (approx. 05-07 LT), which was not noticed in previous studies. As we will discuss in the following section, the Stepwise SCs reported in Araki et al. (1985) and the PPI events defined by Kikuchi and Araki (1985) should be caused by the same mechanism. Therefore, we suggest that the high occurrence rate of the PPI/Stepwise events at the dawn-time dip equator is a new observational result that complements data reported in previous publications (e.g., Araki et al., 1985; Kikuchi and Araki, 1985).

3.2 Araki's model for SC and theoretical calculations

Araki (1994) demonstrated that the SCs observed on the ground are the superposition of two subfields-the DL field and the DP field. The DL field is caused by the enhanced Chapman-Ferraro current, which is transmitted by the compressional waves and is dominant at low latitudes on the ground. The DP field originates in the polar area and is caused by ICs and FACs. The DP field is further decomposed into two parts- $\mathrm{DP}_{\mathrm{PI}}$ and $\mathrm{DP}_{\mathrm{MI}}$ - corresponding to the preliminary sharp impulse $(\mathrm{PI})$ and the following main impulse (MI). The $\mathrm{DP}_{\mathrm{PI}}$ field is caused by a current system, including FACs, that are carried by transverse Alfven waves converted from the compressional hydromagnetic wavefront of the SC propagating in the dayside magnetosphere and by ICs that have a DP2-type structure and are generated by a dusk-to-dawn electric field imposed on the polar ionosphere accompanied with the FACs. The FACs for the $\mathrm{DP}_{\mathrm{PI}}$ field flow into the dusk ionosphere and out from the dawn ionosphere. After the compressional wavefront has propagated toward the magnetotail, a convection electric field in the dawn-to-dusk direction is enhanced in the compressed magnetosphere. The associated FACs, which flow into the dawn ionosphere and out from the dusk ionosphere, also excite a DP2-type IC system with an opposite sense to the preceding $\mathrm{DP}_{\mathrm{PI}}$ current system. The disturbance field caused by this current system (ICs and FACs) is called the DP $\mathrm{DI}_{\mathrm{MI}}$ field (Araki, 1994, and references therein). The physical model for the SC that we have just described has also been quantitatively studied using a numerical simulation approach (Fujita et al., 2003a, b, 2005). Therefore, it is supposed that the magnetosphere-ionosphere current circuit for SC consists of the magnetopause currents (Chapman-Ferraro currents), FACs, and ICs (Kikuchi et al., 2001).

Based on the processes described above and by adopting a realistic distribution of the ionospheric conductivities, including the Cowling effect at the dip equator, Tsunomura and Araki (1984) calculated the magnetic perturbations produced by the ICs (with DP2-type structure) for $\mathrm{DP}_{\mathrm{PI}}$ and $\mathrm{DP}_{\mathrm{MI}}$. Their results explained very well some properties of the latitudinal and LT features of PRI $\left(\mathrm{DP}_{\mathrm{PI}}\right)$ and $\mathrm{DP}_{\mathrm{MI}}$. Tsunomura (1999) further calculated the ground magnetic perturbations generated by FACs and ICs, assuming the application of the Biot-Savart law and introducing asymmetry in the ionospheric conductivity between the northern and southern hemispheres. The FACs in Tsunomura (1999) were assumed to have a normal distribution function of the latitude and LT, with a maximum at 0700 MLT and a minimum at 1700 MLT at $75^{\circ}$ in MAGLAT, and with disper- 

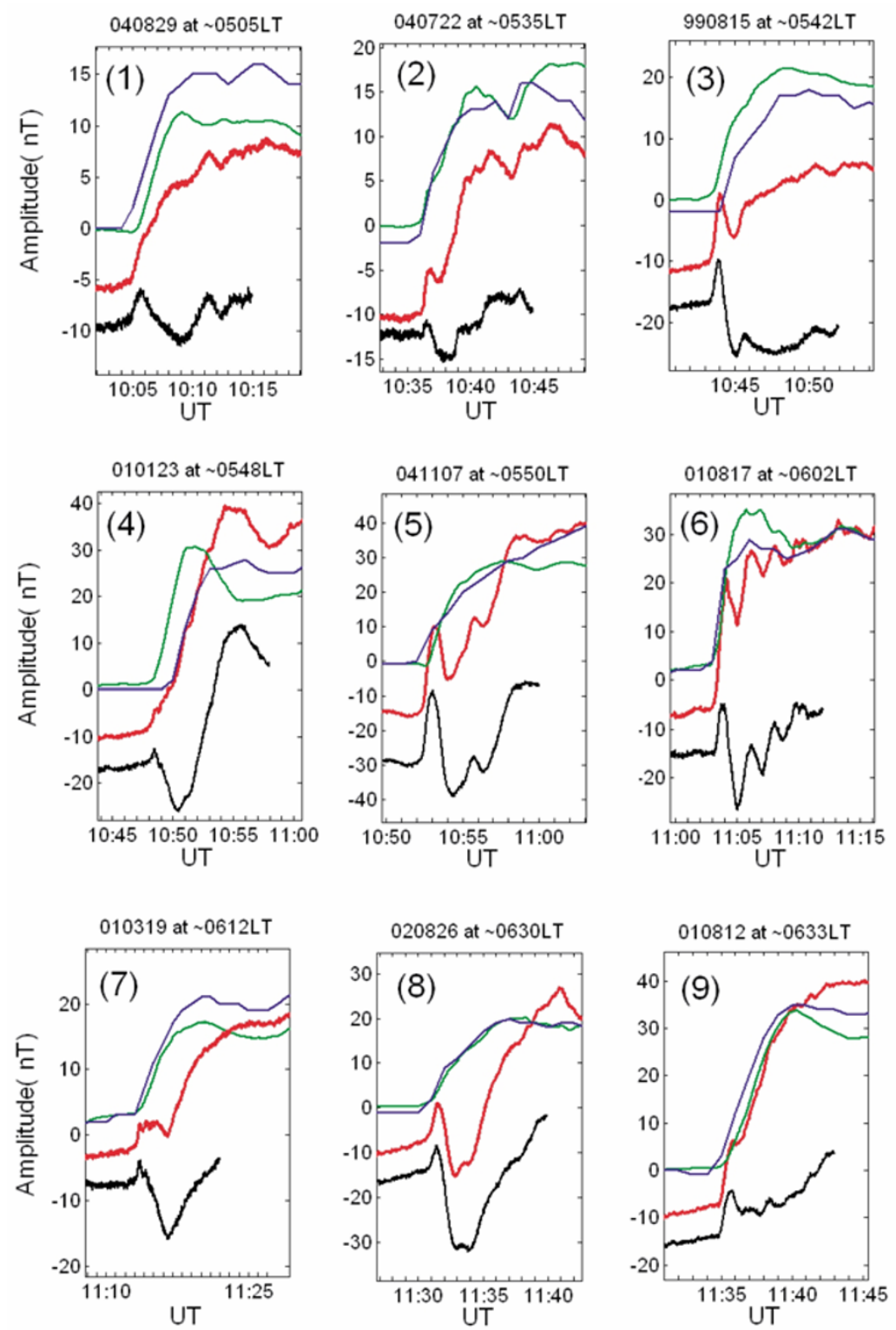

Fig. 3. Plot of the nine PPI/Stepwise SCs observed at the dawn time (05-07 LT) at JIC. The red, green, and blue curves in each panel of Fig. 3 show the SC observed at JIC, KAK, and ABG, respectively. Observation at TAM instead of ABG was used in the event ' 1 '. The date (in format of YYMMDD) and approximate onset time of the SC in LT of JIC are given at the top of each panel. The black curve in each panel shows the waveform of an artificial field of $\delta H$, which is obtained by subtracting the SC field observed at KAK from that at JIC $\left(\delta H=H_{\text {JIC }}-H_{\mathrm{KAK}}\right)$.

Table 2. List of ground stations.

\begin{tabular}{lcrrrrr}
\hline \multirow{2}{*}{ Station name } & \multirow{2}{*}{ Code } & \multicolumn{2}{c}{ Geographic $\left(^{\circ}\right)$} & \multicolumn{2}{c}{ Geomagnetic $\left(^{\circ}\right)$} & \multirow{2}{*}{ Data } \\
\cline { 3 - 5 } & & \multicolumn{1}{c}{ Lat. } & Long. & Lat. & Long. & type \\
\hline Jicamarca & JIC & -12.0 & 283.1 & 0.0 & 354.2 & $1-\mathrm{s}$ \\
Kakioka & KAK & 36.2 & 140.2 & 27.2 & 208.5 & $1-\mathrm{s}$ \\
Alibag & ABG & 18.6 & 72.9 & 10.0 & 146.0 & $1-\mathrm{m}$ \\
Tamanrasset & TAM & 22.8 & 5.5 & 24.7 & 81.6 & $1-\mathrm{m}$ \\
\hline
\end{tabular}

sions $\left(\sigma^{2}\right)$ of $1 / 2\left(2^{\circ}\right)^{2}$ and $1 / 2(3.9 \text { hours })^{2}$ for latitude and LT, respectively. By using the model of Tsunomura (1999) and taking the same realistic distribution of the ionospheric conductivities used in Tsunomura and Araki (1984), Kikuchi et al. (2001) eliminated the effects of the magnetopause currents and calculated the ground $H$ component magnetic fields $(\Delta H)$ produced by FACs and ICs as a function of LT at fixed latitudes. Kikuchi et al. (2001) used a voltage generator model with a constant potential difference of $100 \mathrm{kV}$ between the FACs instead of using constant FAC intensity. The FACs were assumed to flow into the duskside ionosphere and out from the dawnside ionosphere, which is applicable to the $\mathrm{DP}_{\mathrm{PI}}$ field. The results of their calculations for different latitudes (figure 6 of Kikuchi et al., 2001) are shown in Fig. 4 and will be compared with our observational results. 

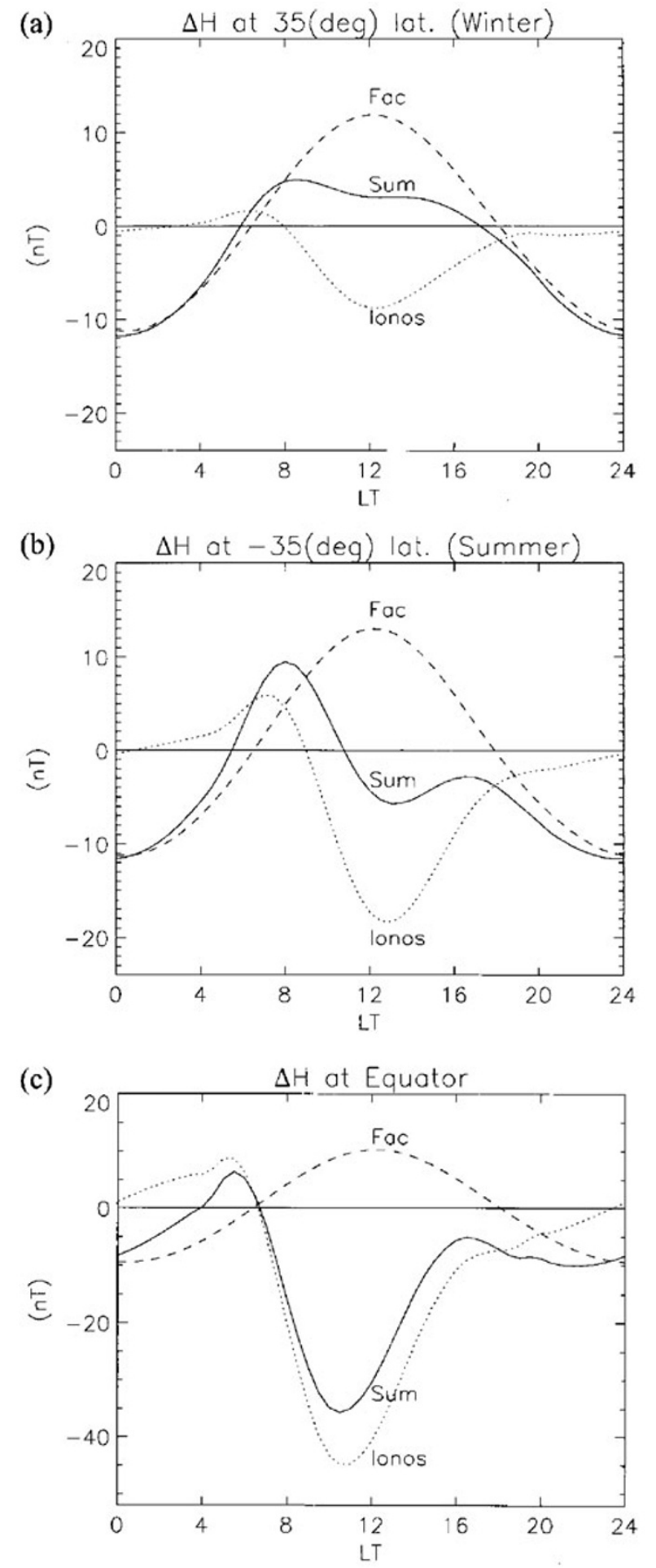

Fig. 4. Model calculations of the ground $H$ component magnetic fields produced by FACs (dashed curve), ICs (dotted curve), and their sum (solid curve) for the $\mathrm{DP}_{\mathrm{PI}}$ field given by Kikuchi et al. (2001): (a) at $35^{\circ}$ geomagnetic latitude in the Northern hemisphere (winter), (b) at $35^{\circ}$ geomagnetic latitude in the Southern hemisphere (summer), (c) at the dip equator (we obtained permission from AGU to use this figure here).

\subsection{Comparison with the model calculation of Kikuchi et al. (2001)}

Figure 4(c) indicates that the $\Delta H$ at the dip equator has positive values at the dawn time (approx. 0400-0700 LT) and negative values at other LTs. This can perfectly ex- plain the PPI/Stepwise events observed at the dawn time, as shown in Fig. 1. Note that Fig. 4(c) gives the result for the $\mathrm{DP}_{\mathrm{PI}}$ field. If we simply assume that the polarity of the $\mathrm{DP}_{\mathrm{MI}}$ field is reversed from that of the $\mathrm{DP}_{\mathrm{PI}}$ field, the $\mathrm{DP}_{\mathrm{PI}}$ and $\mathrm{DP}_{\mathrm{MI}}$ fields will produce an increase and a decrease disturbance at the dawn-time dip equator, respectively. Therefore, according to the physical process described in Araki's model, the increases observed at beginning of the PPI/Stepwise events and the decreases following these increases correspond to the $\mathrm{DP}_{\mathrm{PI}}$ and $\mathrm{DP}_{\mathrm{MI}}$ fields, respectively. We noticed that the effect of the $\mathrm{DP}_{\mathrm{MI}}$ field at the dawn-time dip equator can even be so strong that it makes the waveforms of SCs totally anomalous, as shown in events '7' and ' 8 '; this could result from the FACs for the $\mathrm{DP}_{\mathrm{PI}}$ and $\mathrm{DP}_{\mathrm{MI}}$ fields having significant differences, such as on the intensity, latitude of the footprint, and temporal variation of the footprint.

Because the result in Fig. 4(c) eliminates the effects of the magnetopause currents-i.e., only shows the DP field caused by the FACs and ICs-and the observations at JIC consist of both the DL and DP fields, we need to subtract the DL field from the JIC observations to make a clear comparison. Russell et al. (1992) concluded that the simplest response to sudden changes in solar wind dynamic pressure occurs at low latitudes from $15^{\circ}$ to $30^{\circ}$ in latitude, where the effects of both the equatorial and auroral eletrojets are minimal. In addition, a recent study by Han et al. (2007b) found that the waveforms of the SCs observed just above the ionosphere on the nightside are almost the same as those observed on the ground beneath the satellite, which indicates that the ICs have little effects on the nightside observations of the SC. Therefore, we suggest that the SC field observed at a low-latitude station on the nighttime could be the most direct and the simplest estimation for the DL field. Consequently, we examined the waveform of the artificial field (as shown by the black curves in Fig. 3), which was obtained by subtracting the SC field observed at KAK from that observed at JIC, in order to estimate the DP field observed at JIC. A similar approach was also used by Kikuchi et al. (2001) to estimate the DP field, but in contrast to these authors, we used the SC field observed at a low-latitude station on the nighttime (i.e., at KAK) rather than one observed at a low-latitude station located in the same LT sector as JIC. We argue that using the nighttime low-latitude observation is better than using the observation at the same LT sector as JIC, because the ICs have little effects on the nighttime observations of the SC (Han et al., 2007b), and the waveforms of SC at the low latitudes in the morning sector can often be severely deformed from a simple step-like structure, which indicates the effects of the DP field (such cases can be easily found in previous studies; for example, Russell et al., 1994a, b).

Figure 4 shows that the $\mathrm{DP}_{\mathrm{PI}}$ fields caused by the FACs at $35^{\circ}$ latitude at approximately 18-21 LT (corresponds to the KAK observations in Fig. 3) and at the equator at approximately 04-07 LT (corresponds to the JIC observations in Fig. 3) are around $-5.0 \mathrm{nT}$ and $-2.5 \mathrm{nT}$ (refer to the medians during the periods), respectively. Figure 4 also shows that the DP $\mathrm{PI}_{\mathrm{PI}}$ field caused by ICs at $35^{\circ}$ latitude and at approximately $18-21 \mathrm{LT}$ is very small, especially for the win- 
ter hemisphere. That is, when we use the artificial field of the $\delta H\left(H_{\mathrm{JIC}}-H_{\mathrm{KAK}}\right)$ to estimate the DP field at JIC, a fraction of the DP field caused by the FACs could be eliminated or even overeliminated. Therefore, the black curves in Fig. 3 may be regarded as a coarse estimation of the DP field at JIC that is predominantly caused by the ICs.

The black curves in Fig. 3 demonstrate that an increasedecrease impulsive variation can be seen for all of the events shown in Fig. 4. When we consider that the $\mathrm{DP}_{\mathrm{PI}}$ field is the first to be excited and that the $\mathrm{DP}_{\mathrm{MI}}$ field is generated later, as depicted in Araki's model, the increase-decrease variation is consistent with what is predicted by the model calculation of Kikuchi et al. (2001). Such an impulsive DP field superposed on a simple step-like DL field can cause the SC waveforms to show what seems like to be PPI/Stepwise events, so we suggest that the frequent occurrence of the PPI/Stepwise events at the dawn time is consistent with the model calculation of Kikuchi et al. (2001).

Figure 4(c) shows that the disturbance field at the nighttime dip equator (approx. 0000-0400 LT) caused by the ICs (dotted line) is positive and that caused by the FACs is negative, which leads to the total disturbance field (solid line) being negative. According to this result, PRI events should be observed during the nighttime period. However, the observational result shows that only PPI/Stepwise events-but no PRI events-were observed at JIC during the nighttime. Nevertheless, the FACs will produce negative disturbance fields at the nighttime dip equator, so we suggest that the positive impulsive disturbance of the PPI/Stepwise events observed there should mainly be caused by the ICs, which is consistent with what was suggested by Araki et al. (1985). We also suggest that the existence of the FAC effects may decrease the occurrence rate of the PPI/Stepwise events there. This could be the reason for the low occurrence rate of the PPI/Stepwise events observed at the nighttime dip equator, as shown in Fig. 1 and Table 1.

\section{Conclusion}

We found that a minor part of the SCs observed at the nighttime dip equator shows PPI/Stepwise structure, which is basically consistent with what was described by Araki et al. (1985). We also found that a high percentage of the SCs observed at the dawntime dip equator are PPI/Stepwise events, which has not been reported before. We argue that this observational result is complementary to previous works in this area as well as to our understanding of the ground response to sudden changes of the solar wind parameters in morphological. Finally, we also argue that this observational result provides evidence for the validity of the model calculation of Kikuchi et al. (2001).

Acknowledgments. We would like to state our honest appreciation to T. Araki for his continuous instructions and help. The authors thank P. Chi for providing the magnetic field data at Jicamarca from the UCLA ground magnetometer data center. The authors thank the World Data Center for Geomagnetism in Kyoto for supplying the ground magnetic field data. This research was supported by the National Science Foundation of China (NSFC grant No. 40504009). A portion of this work was supported by the project Environment Building for S\&T Industries (2005DKA64000) and MOST International Collaboration project 2005DFA20970.

\section{References}

Araki, T., Global structure of geomagnetic sudden commencements, Planet. Space Sci., 25, 373-384, 1977.

Araki, T., A physical model of geomagnetic sudden commencement, in Solar Wind Sources of Magnetospheric Ultra-Low-Frequency Waves, Geophys. Monogr. Ser., 81, edited by M. J. Engebretson, K. Takahashi and M. Scholer, p. 183, AGU, Washington, D.C., 1994.

Araki, T., J. H. Allen, and Y. Araki, Extension of a polar ionospheric current to the nightside equator, Planet. Space Sci., 33(1), 11-16, 1985.

Fujita, S., T. Tanaka, T. Kikuchi, K. Fujimoto, K. Hosokawa, and M. Itonaga, A numerical simulation of the geomagnetic sudden commencement: 1. Generation of the field-aligned current associated with the preliminary impulse, J. Geophys. Res., 108(A12), 1416, doi:10.1029/2002JA009407, 2003a.

Fujita, S., T. Tanaka, T. Kikuchi, K. Fujimoto, and M. Itonaga, A numerical simulation of the geomagnetic sudden commencement: 2. Plasma processes in the main impulse, J. Geophys. Res., 108(A12), 1417, doi:10.1029/2002JA009763, 2003b.

Fujita, S., T. Tanaka, and T. Motoba, A numerical simulation of the geomagnetic sudden commencement: 3 . A sudden commencement in the magnetosphere-ionosphere compound system, J. Geophys. Res., 110, A11203, doi:10.1029/2005JA011055, 2005.

Han, D.-S., H.-G. Yang, Z.-T. Chen, T. Araki, M. W. Dunlop, M. Nosé, T. Iyemori, Q. Li, Y.-F. Gao, and K. Yumoto, Coupling of perturbations in the solar wind density to global Pi3 pulsations: A case study, J. Geophys. Res., 112, A05217, doi:10.1029/2006JA011675, 2007a.

Han, D.-S., T. Araki, H.-G. Yang, Z.-T. Chen, T. Iyemori, and P. Stauning, Comparative study of Geomagnetic Sudden Commencement (SC) between Oersted and ground observations at different local times, J. Geophys. Res., 112, A05226, doi:10.1029/2006JA011953, $2007 \mathrm{~b}$.

Kikuchi, T. and T. Araki, Preliminary positive impulse of geomagnetic sudden commencement observed at dayside middle and low latitudes, J. Geophys. Res., 90, 12195-12200, 1985.

Kikuchi, T., S. Tsunomura, K. Hashimoto, and K. Nozaki, Field-aligned current effects on midlatitude geomagnetic sudden commencements, $J$. Geophys. Res., 106, 15555-15565, 2001.

Matsushita, S., On geomagnetic sudden commencements, sudden impulses, and storm durations, J. Geophys. Res., 67, 3753-3777, 1962.

Motoba, T., T. Kikuchi, H. Lühr, H. Tachihara, T.-I. Kitamura, K. Hayashi, and T. Okuzawa, Global Pc5 caused by a DP 2-type ionospheric current system, J. Geophys. Res., 107(A2), 1032, 10.1029/2001JA900156, 2002.

Russell, C. T. and M. Ginskey, Sudden impulses at subauroral latitudes: Response for northward interplanetary magnetic field, J. Geophys. Res., $100(A 12), 23,695-23,702,1995$.

Russell, C. T., M. Ginskey, S. Petrinec, and G. Le, The effect of solar wind dynamic pressure changes on low and mid-latitude magnetic records, Geophys. Res. Lett., 19, 1227, 1992.

Russell, C. T., M. Ginskey, and S. M. Petrinec, Sudden impulses at lowlatitude stations: Steady state response for northward interplanetary magnetic field, J. Geophys. Res., 99, 253-261, 1994a.

Russell, C. T., M. Ginskey, and S. M. Petrinec, Sudden impulses at low latitude stations: Steady state response for southward interplanetary magnetic field, J. Geophys. Res., 99, 13,403-13,408, 1994b.

Shinohara, M., K. Yumoto, N. Hosen, A. Yoshikawa, H. Tachihara, O. Saka, T. I. Kitamura, N. B. Trivedi, J. M. Da Costa, and N. J. Schuch, Wave characteristics of geomagnetic pulsations across the dip equator, J. Geophys. Res., 103, 11745-11754, 1998.

Tamao, T., The structure of three-dimensional hydromagnetic waves in a uniform cold plasma, J. Geomag. Geoelectr., 18, 89-114, 1964.

Tsunomura, S., Numerical analysis of global ionospheric current system including the effect of equatorial enhancement, Ann. Geophys., 17, 692$706,1999$.

Tsunomura, S. and T. Araki, Numerical analysis of equatorial enhancement of geomagnetic sudden commencement, Planet. Space Sci., 32, 599-604, 1984.

Tsunomura, S., Characteristics of geomagnetic sudden commencement observed in middle and low latitudes, Earth Planets Space, 50, 755$772,1998$.

D.-S. Han (e-mail: handesheng@pric.gov.cn) and Q. Li 